\title{
AN ANALYSIS OF CLAIM EXPERIENCE IN PRIVATE HEALTH INSURANCE TO ESTABLISH A RELATION BETWEEN DEDUCTIBLES AND PREMIUMI REBATES
}

\author{
G. W. DE WIT and W. M. KAstelijN
}

Many studies concerning the frequency of claims by size in health insurance are not generally known *). A possible explanation of this circumstance could be the fact that in most countries this line of insurance has been brought entirely within the ambit of social insurance. Also from the side of the social insurance very few investigations have been published ${ }^{* *}$ ).

In this paper we will analyse the claim experience (relating to the calendar year I972) of a private health insurance business. The data have been subdivided according to three levels of coverage (in increasing order of benefits these are: class III, class IIb and class IIa). The claim payments comprise nursing costs, auxiliary costs and the fees for specialist treatment in and out of the hospital.

We will use the following notations:

$s_{i}$ : claim amount paid for the insured $i$ in one year,

$n$ : number of claims,

$v$ : number of risks (policies insured).

In many instances the premium is simply determined as a level premium. In other words each insured pays the premium $p$, calculated as follows:

$$
p=\frac{\Sigma s_{i}}{v}
$$

*) Notably concerning West Germany and Switzerland we refer to some recent articles published in the Blätter der Deutschen Geseilschaft für Versicherungsmathematik and in the Mitteilungen der Vereinigung Schweizerischer Versicherungsmathematiker.

**) See e.g. the analysis made in Finland (Research Institure fot Social Security). 
Actually we make the assumption that the claims are normally distributed, the parameters of which can be estimated as follows:

$$
\begin{gathered}
\mu=\frac{I}{n} \Sigma s_{i} \\
\sigma^{2}=\frac{I}{n}-I \Sigma\left(s_{i}-\mu\right)^{2}
\end{gathered}
$$

which permits the calculation of the premium according to:

$$
p=\frac{n}{v} \mu
$$

Plotting the empirical claim distribution on log-normal probability paper suggests however that (like many other distributions in the field of insurance) the log-normal assumption gives a better fit than the normal distribution. Denoting its parameters by $\mu$ and $\sigma$ its mean and variance are:

$$
\begin{aligned}
\alpha & =\exp \left\{\mu+\frac{1}{2} \sigma^{2}\right\} \\
\beta^{2} & =\exp \left\{\sigma^{2}-I\right\} \exp \left\{2 \mu+\sigma^{2}\right\} .
\end{aligned}
$$

The premium can again be found as:

$$
p=\frac{n}{v} \alpha \text {. }
$$

The parameters of the log-normal distribution can be estimated by means of various methods (Aitchison and Brown: The lognormal distribution). For our purposes we used logarithmic probability paper (absciss: logarithmic; ordinate: probability). This approach has the advantage that besides estimation of the parameters we can test whether the data look like a log-normal distribution.

For our estimations and tests of log-normality we started from the following data: 
TABLE I

\begin{tabular}{|c|c|c|c|c|c|c|}
\hline $\begin{array}{l}\text { Claim } \\
\text { amount s }\end{array}$ & $\begin{array}{l}\text { Class } \\
\text { Number } \\
\text { of claims } \\
\leqslant s\end{array}$ & $\begin{array}{l}\text { III } \\
\% \text { claims } \\
\leqslant s\end{array}$ & $\begin{array}{l}\text { Class } \\
\text { Number } \\
\text { of claims } \\
\leqslant s\end{array}$ & $\begin{array}{l}\text { IIb } \\
\% \text { claims } \\
\leqslant s\end{array}$ & $\begin{array}{l}\text { Class } \\
\text { Number } \\
\text { of claims } \\
\leqslant s\end{array}$ & $\begin{array}{c}\% \text { claims } \\
\leqslant s\end{array}$ \\
\hline 100 & 801 & I9.5 & 579 & I8. I & 244 & I 8.2 \\
\hline 200 & $\mathrm{I}_{434}$ & 34.9 & 1037 & 32.5 & 424 & 31.6 \\
\hline 300 & I806 & 44.0 & I $33^{6}$ & 41.9 & 527 & $39 \cdot 3$ \\
\hline 400 & $2 I I 3$ & 51.4 & I 564 & 49.0 & 625 & 46.6 \\
\hline 500 & 2367 & 57.6 & I $75^{6}$ & 55.0 & 698 & 52.0 \\
\hline 600 & 2557 & 62.2 & 1899 & 59.5 & 754 & 56.2 \\
\hline 700 & 2675 & $65 . I$ & 2007 & 62.9 & 795 & 59.2 \\
\hline 800 & 2789 & 67.9 & 2093 & 65.6 & 831 & 61.9 \\
\hline 900 & 2880 & 70.1 & 2162 & 67.7 & 866 & 64.5 \\
\hline 1000 & 2969 & 72.3 & 2219 & 69.5 & 895 & 66.7 \\
\hline I 500 & 3282 & 79.9 & 2440 & 76.4 & 994 & $74 . I$ \\
\hline 2000 & 3479 & 84.7 & 2589 & $8 \mathrm{I} . \mathrm{I}$ & 1068 & 79.6 \\
\hline 2500 & 3623 & 88.2 & 2686 & $84 . I$ & ro97 & $8 \mathrm{r} .7$ \\
\hline 3000 & 3734 & 90.9 & 2768 & 86.7 & 1128 & 84.1 \\
\hline 4000 & $3^{8} 73$ & 94.3 & 2882 & 90.3 & I I 84 & 88.2 \\
\hline 5000 & 3945 & 96.0 & 2968 & 93.0 & 1219 & 90.8 \\
\hline 7000 & $4 \mathrm{OI}_{4}$ & 97.7 & 3069 & 96.I & I $27^{\circ}$ & 94.6 \\
\hline roroo & 4055 & 98.7 & 3135 & 98.2 & I 303 & $97 . I$ \\
\hline 20400 & 4097 & 99.7 & $3 I_{3}$ & 99.7 & I34 I & 99.9 \\
\hline$\infty$ & 4108 & 100 & 3192 & 100 & I 342 & IOO \\
\hline
\end{tabular}

The percentages of claims $\leq s$ are plotted on log-normal probability paper. If the sample points ly approximately on a straight line it is reasonable to assume log-normality. This appears to be the case for each of the three classes (figures $I a, I b, I c$ ).

From the graph we can calculate $\mu$ and $\sigma$. The points $s_{50}$ (the median) and $s_{95}$ can be read from the graph. The two parameters are then determined as follows:

$$
\begin{aligned}
\mu & =\log s_{s 0} \\
\text { and } \sigma & =\log \frac{s_{95}}{s_{50}} / \mathrm{I} .645 .
\end{aligned}
$$

For class III we then find:

$$
\begin{aligned}
& \mu=\log 400=5.99 \\
& \sigma=\log \frac{42 \mathrm{IO}}{400} / \mathrm{r} .645=\mathrm{r} .43 \mathrm{I}
\end{aligned}
$$

carrying through the calculations for all possibilities results in the following table: 


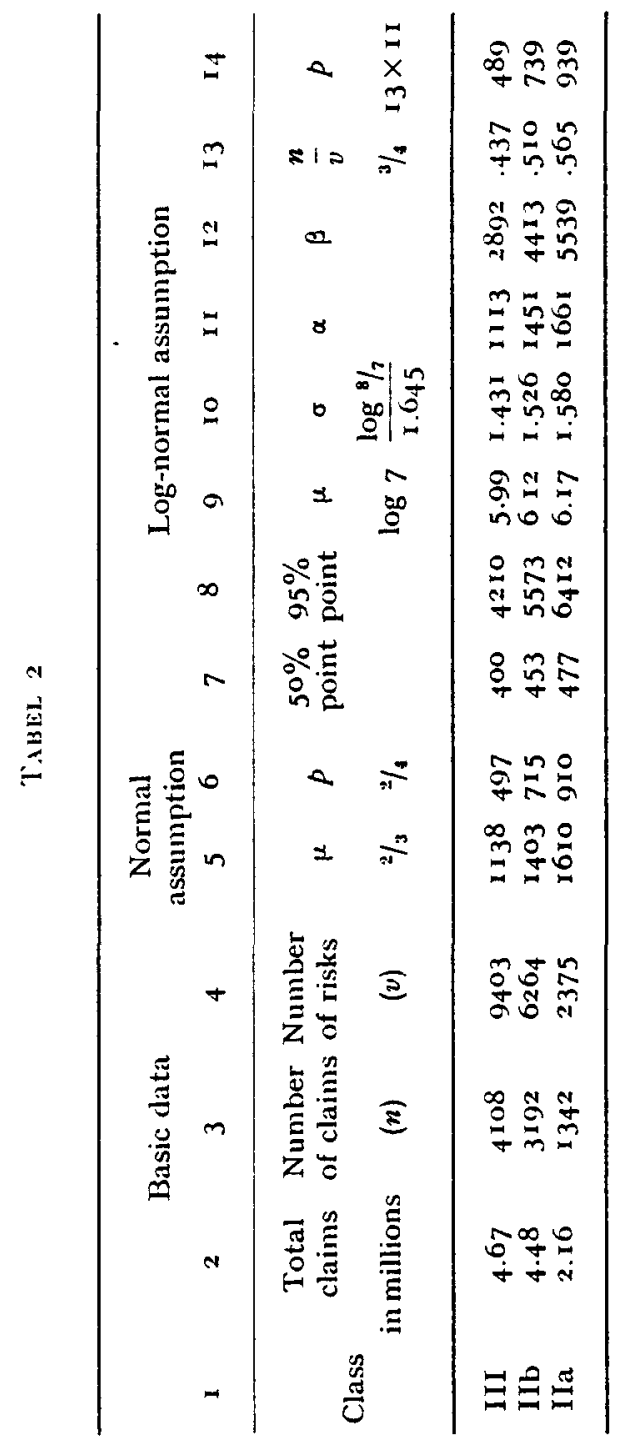




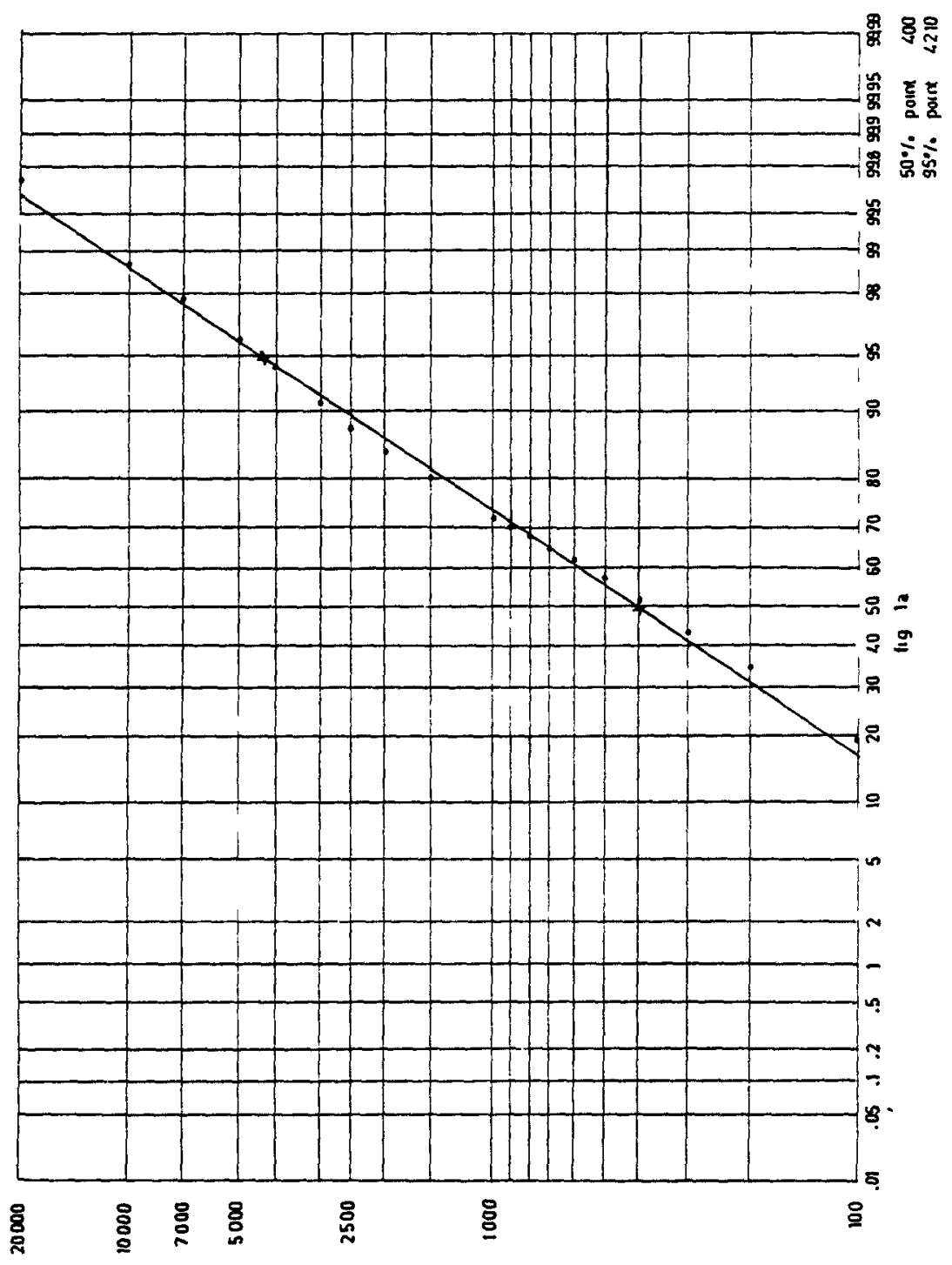




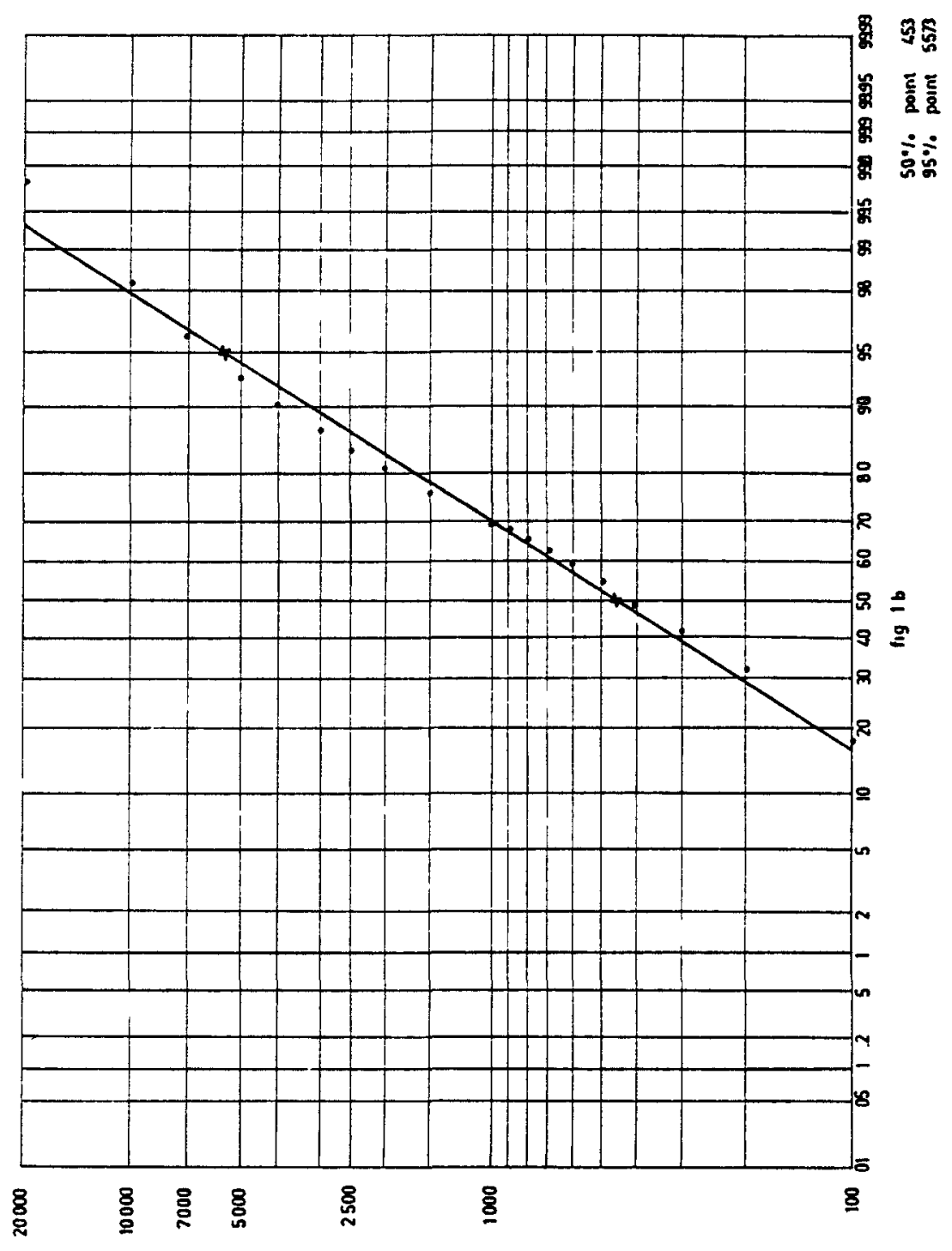




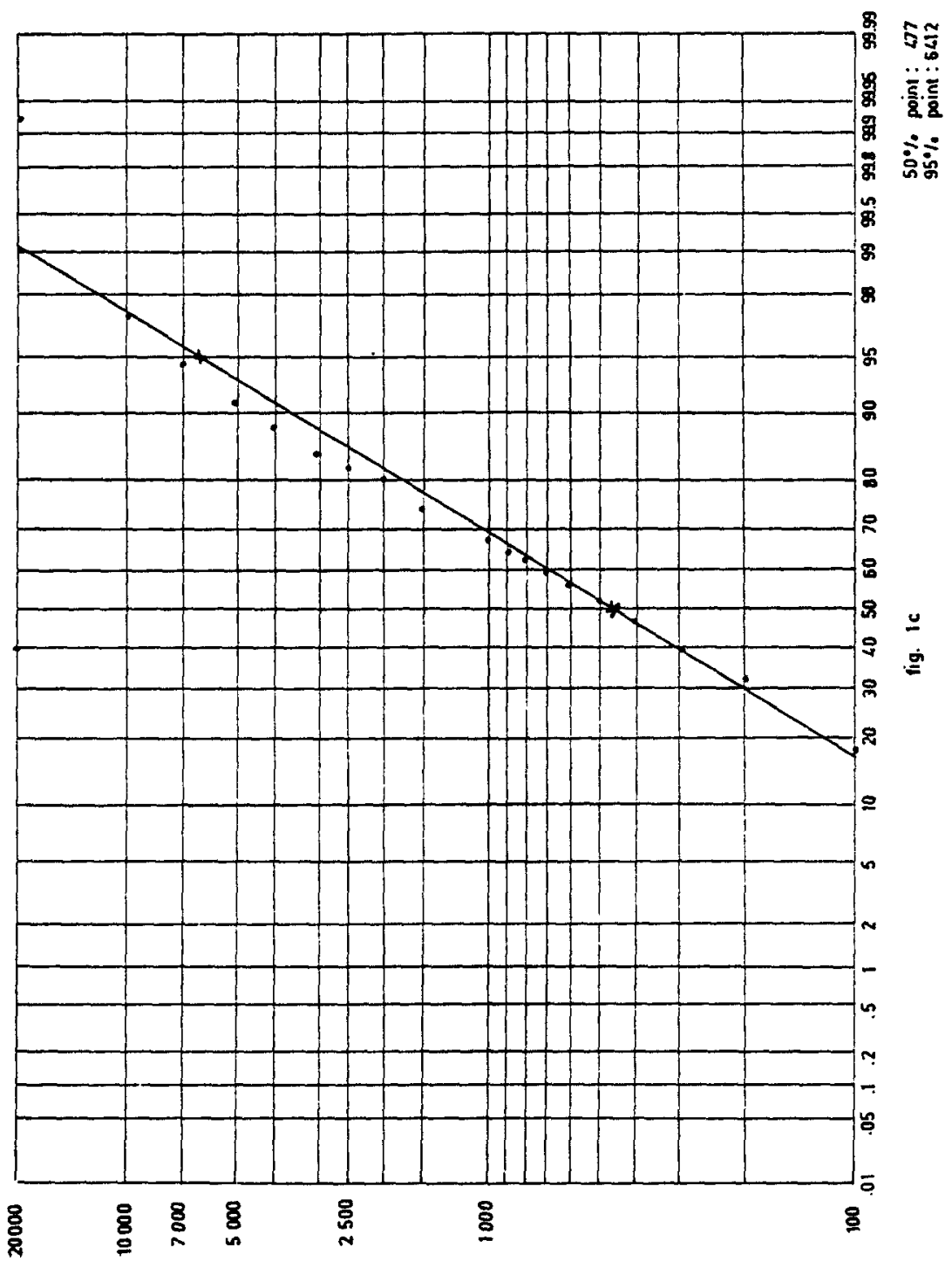


A "disadvantage" of this method is that the sum of the premiums does not equal the sum of the claims. It seems however questionable whether this is really a disadvantage. If we apply the present premium estimation method to a later year it will give a better quarantee for the adequacy of the rating than the requirement of strict equivalence.

In the foregoing we have considered how the level premium can be derived from the empirical claim distribution. We can also reverse this question: in what manner does this claim distribution depend on the premium.

Knowing the premium is however not sufficient to find the claim distribution, because for that purpose we also have to know the variance and $(n / v$.$) It turns out, however, that a relation exists$ between the quantities $p$ and $\beta$ on the one hand and between $(n / v)$ and $p$ on the other hand. If we know this relation we are in a position to find $\beta$ and $(n / v)$ directly from $p$ and $\alpha$ by means of (3).

Figures $2 \mathrm{a}$ and $2 \mathrm{~b}$ show that both relations are linear:

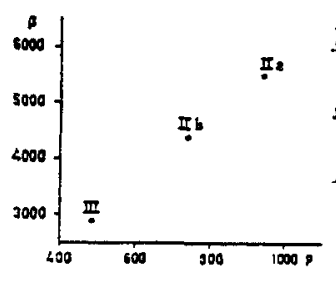

Fig. 2a

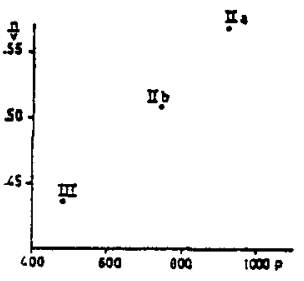

Fig. $2 b$

The linear relations are:

$$
\begin{aligned}
\beta & =5.85 p+6 \mathrm{I} . \mathrm{I} \\
(n / v) & =.000283 p+.30
\end{aligned}
$$

( 1$),(2)$ and (3) can be written as:

$$
\begin{aligned}
& \alpha=\frac{p}{\left(\frac{n}{v}\right)} \\
& \mu=\log \left(\frac{\alpha^{4}}{\beta^{2}+\alpha^{2}}\right) \\
& \sigma^{2}=\log \left(\frac{\beta^{2}+\alpha^{2}}{\alpha^{2}}\right)
\end{aligned}
$$


The last three formulae allow us to calculate $\beta,(n / v), \mu$ and $\sigma^{2}$ successively for given $p$. We thus have found the distribution we require. The claim distribution as a function of the premium also permits the calculation of the premium rebate for a given deductible. Let $f(s ; p)$ be the claim distribution and $\varphi(R, p)$ the rebate factor applicable to the premium as a function of the deductible $R$ and the premium. Then the following relation exists:

$$
\varphi(R, p)=\frac{\int_{0}^{R} s f(s ; p) d s+R \int_{R}^{\infty} f(s ; p) d s}{\int_{0}^{\infty} s f(s ; p) d s .}
$$

Actual calculations for various $p$ and $R$ result in the following table for $\varphi(R, p)$ :

TABLE 3

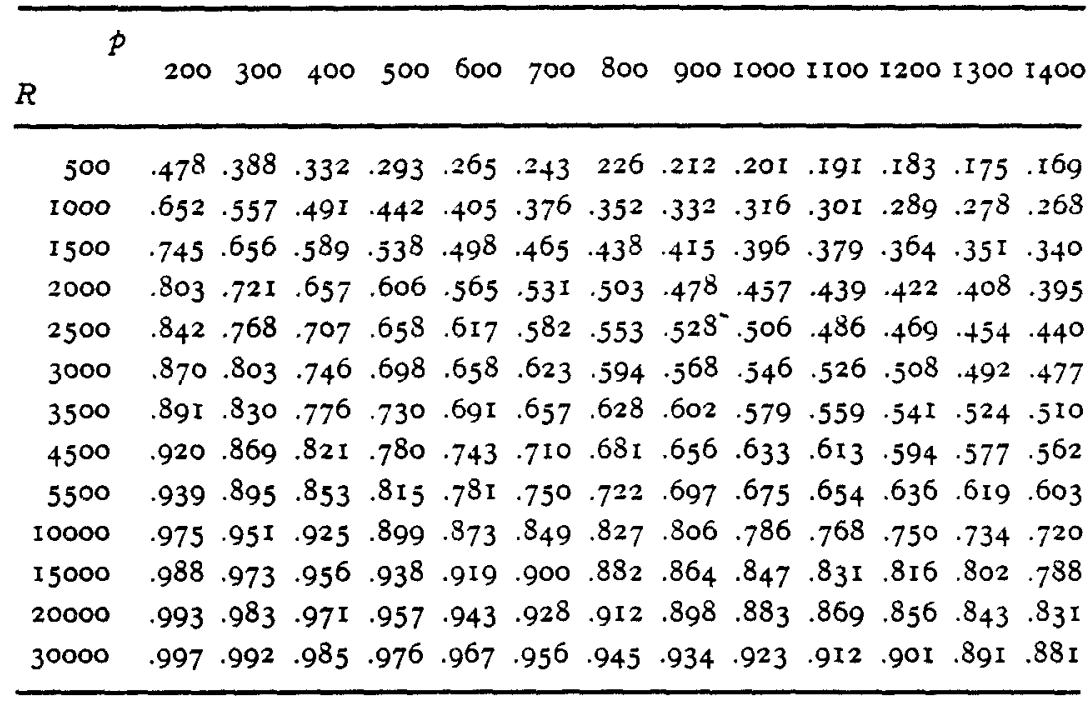

Up till now we have assumed throughout that both the level premium and the claim distribution are independent of the age of the insured. This assumption is actually not justified. Usually the claim amount is age dependent as follows:

$$
s_{x}=c_{0} \cdot c_{1}^{x} .
$$


Here $c_{0}$ and $c_{1}$ are constants. Estimation of these constants from the data available for 1972 produced the following results:

\begin{tabular}{lcccc}
\hline \multirow{2}{*}{ Class } & \multicolumn{2}{c}{ Males } & \multicolumn{2}{c}{ Females } \\
& $c_{0}$ & $c_{1}$ & $c_{0}$ & $c_{1}$ \\
\hline III & 62.0 & I 034 & I65.5 & 1.02I \\
IIb + IIa & 54.4 & 1.045 & 230.9 & I.02 I \\
\hline
\end{tabular}

The constant $c_{1}$ is as a matter of fact time dependent with respect to the level of medical care and consequently will change only very slowly with time. The constant $c_{0}$ on the other hand reflects the price level of medical care of which it is directly dependent.

The calculation of $s_{x}$ has been carried out however assuming normality. With the log-normal assumption the age dependence of $\alpha, \beta$ and $(n / v)$ will have to be studied. The extent of the claim data available was not, however, of sufficient size to justify a subdivision by age. Hence, the age dependence of $\beta$ and $(n / v)$ could not be examined. 